\title{
14. Living and theorizing boundaries of justice
}

\author{
Trudie Knijn, Jelena Belic and Miklós Zala
}

\subsection{INTRODUCTION}

This chapter integrates the ETHOS empirical findings as described in the previous chapters with the project's main theoretical framework founded on Fraser's 'three Rs': redistributive, recognitive and representative justice, and further developed in the ETHOS research programme, as outlined in the introduction of this volume. The chapter elaborates and conceptualizes the most important dimensions along which drawing boundaries of justice takes place. Drawing boundaries relates to the processes of inclusion in or exclusion from the 'scope of justice' - the group to which one 'owes' or within which one can legitimately claim what is her 'due'. 'Owing' to others and claiming one's 'due' stand for the most stringent obligations regarding claims for redistribution, recognition and representation. In the Fraserian framework, justice ultimately requires 'participating as peers' in a democratic society, and exclusion from such participation amounts to 'a grave moral wrong' (2007, p. 314). The chapter shows that exclusion and inequality are present across the borders of political communities as well as within them in institutional settings and in discourses and social practices. The assumption is that such boundary lines, which we call fault lines of justice, are historically dynamic and contextually contested and debated.

Institutionalized (in)justice materializes in drawing boundaries of justice between citizens and non-citizens on arbitrary and/or formal (legal) bases. Formal exclusion and unequal treatment of non-citizens are justified by them not having a claim to the legal citizenship status. Although the dominant discourse and practice is that formal belonging to political community is necessary to be included in the scope of justice, having citizenship status alone is not sufficient to be protected against exclusion and inequality on institutionalized grounds as well as in social practice. The previous chapters discuss various intersecting boundary lines in the European Union (EU) and its Member States including ethnicity, religion, gender, age, physical able-ness, as well as social 
economic positions such as being unemployed, living on social benefits or working in undervalued sectors (such as care) and/or on precarious contracts. Differentiation in exclusion from/inclusion in the scope of justice means that those excluded are 'vulnerable' to further injustices because they either have no right to claim what is their 'due' such as decent income, housing, education and political participation, or cannot claim it effectively. Moreover, they are denied dignity, respect and recognition, all of which are needed to live a life one values. In what follows we first generalize from the various empirical findings in order to categorize boundaries of justice, and then use these categories as the basis to refine the ETHOS's theoretical framework.

The chapter is structured as follows. We start by clarifying our methodological approach. In the next section, we problematize external boundaries of justice as limited by territorially bounded political communities and manifested in national citizenship. In the following section, we conceptualize internal boundaries of justice by drawing on Fraser's notion of 'institutionalized patterns of subordination and exclusion'. We then explain the ways in which the existing forms of categorizations lead to exclusion, and in the subsequent section, we conceptualize categorizations along the lines of age, ethnicity, ability and gender. Finally, we end by refining the ETHOS's theoretical framework based on these categorizations.

\subsection{METHODOLOGICAL CLARIFICATION}

The chapter employs the method of moving back and forth between philosophical principles of justice and empirical findings of the ETHOS project. The first three chapters of this volume outline the philosophical approach to justice (see Chapters 2 to 4), and the subsequent chapters (Chapters 5 to 11) describe and interpret the empirical findings. In this chapter, we refine the ETHOS's theoretical framework by integrating the philosophical arguments and the empirical findings regarding drawing boundaries of justice. The aim is to make final steps in defining the building blocks of a more coherent understanding of justice in Europe.

The ETHOS empirical studies as presented in the previous chapters come to a critical analysis based upon various kinds of data (discourses, legal regulations, document analyses, ethnographies, interviews, focus groups and secondary analyses of surveys), they focus on different themes (housing, voting, education, care, work and income) and address different populations that are subject to social exclusion and thus became vulnerable (ethnic minorities, fragile elderly, young women, disabled people), and as such do not lend themselves to a simple aggregation. Thus, in order to juxtapose the diverse empirical findings with the philosophical principles of justice, we employ the Weberian approach to 'arrive at concepts that, while they do not reflect empir- 
ical reality strictly speaking, nevertheless provide heuristically useful idealizations that allow one to better grasp and typologize social phenomena' (Knijn and Lepianka 2018; Theuns et al. 2019, p. 13; see also Chapter 4). ${ }^{1}$ Here we will use this approach to formulate categories of boundary drawing as revealed by the critical evaluation of our empirical studies. This can secure a bottom-up theory construction and inclusion of subjective experiences of marginalized persons, while at the same time enabling generalization from such experiences in order to identify shared values and practices.

\subsection{BOUNDARY DRAWING BETWEEN CITIZENS AND NON-CITIZENS}

Political communities were and still are inherently exclusive since they limit the scope of justice to 'own citizens'. It is believed that formal belonging to a territorially bounded political community manifested in the legal status of citizenship defines the scope of justice (Walzer 1983; Miller 1995; Nagel 2005). In Europe, the EU and beyond, this view has become increasingly challenged since it excludes those beyond borders of political communities and is also blind to various forms of exclusion that take place within political communities.

Historically speaking, the emerging idea and practice of modern citizenship had an inclusionary and equalizing impetus by virtue of creating the identity of an 'imagined community' (the modern nation) (Anderson 1983) as well as by extending the legal status of citizens to all those belonging to a territorially bounded political community (the state). Within these communities the scope of rights as well as the scope of their holders have been gradually extended to reach its peak with the introduction of what Marshall (1950) termed as 'social citizenship' in the post-World War II European welfare state. In Marshall's view, social citizenship presents the culmination of the universalist tendencies of citizenship since it accords the identical set of civil, political and social rights to all members of polity to compensate for the stratifying hierarchies generated by the capitalist markets.

The initial aims of citizenship were also to exclude 'the others' - those who are seen as not belonging to European nation states even if they were subjected to their rule. The ongoing processes of growing global interdependence make national citizenship even more exclusionary along three dimensions: territorial affectedness, sedentariness and national belonging. These three lines are not distinctive of national citizenship in Europe but characterize the concept of national citizenship as such.

National citizenship presupposes a territorially bounded political community whose members are equally affected by the community's decisions and therefore have the claim to participate in making these decisions. As Lepianka 
(2018) shows, even political actors with more universalist aspirations calling themselves 'social democrats' direct their agendas strictly to citizens. Such views deny that all those affected by a polity's decisions have the right to have a say in the polity's decision-making and assume that the affectedness is limited to the polity's members only. However, given the EU integration, global interdependence of economies, environment, communication and movement, affectedness by a community's laws and decisions extends far beyond its borders as the failure to adequately address climate change, war refugees, mobile EU citizens and the reiterating financial crises are painfully showing (Fraser 2009). ${ }^{2}$ If affectedness is the basic principle for recognizing the right to the legal status of a citizen as well as to a bundle of rights it entails, including the access to resources, then ignoring the cross-border affectedness amounts to arbitrarily excluding those who are significantly affected by the decisions of the national or European community. The Westphalian division of political space into bounded polities amounts to the injustice of 'misframing' since it has created the frame of the disputes about justice that wrongly excludes some from consideration (Fraser 2007).

The second line of exclusion from national citizenship is assumed sedentariness of the population: the idea that citizens have long-term ties to a specific territory (Anderson and Dupont 2018; see also Chapter 8). The sedentarist character of national citizenship creates boundary lines of justice by fault or default for those who move around. When it comes to groups that are dispersed across borders, Anderson and Dupont (2018) highlight how assuming sedentariness generates the problem of political representation of Roma - in order to be represented, they need to be included into national institutions designed according to the needs and interests of the majoritarian, sedentarist population, and this amounts to the misrecognition of Roma. The distinction between sedentary and mobile populations became even more salient with the introduction of EU citizenship in the 1990s in order to secure the partial inclusion of EU internal migrants in their new residence countries by recognizing their additional rights on the basis of freedom of movement. This created a fault line between mobile EU nationals and third country nationals who acquire additional rights in a much harder way, if at all. This is especially problematic given that many of the third country nationals belong to populations of the former European colonies and have contributed to the wealth of current Europe (Oomen and Timmer 2017; see Chapter 5). EU mobile nationals, in turn, are still disadvantaged compared to local sedentary citizens since they typically do not have access to full social rights and participation in decision-making (Theuns 2019). Hence, mobile EU citizens can appear both advantaged and disadvantaged depending on which population they are compared to. To identify fault lines of justice, we need to define relevant reference points since disadvantages are always positional and relative to another group or person 
compared. Going back to the EU citizenship, one can say that it generated fault lines between EU mobile nationals, third country nationals and local (sedentary) citizens. The further complication arises from the imperative to make 'mobile' migrants more 'sedentarist' by attempting to connect them to territories via residence requirements often depending on their employment. This places migrants in a dependent position with regard to their employers and, consequently, makes them vulnerable to exploitation (Meneses et al. 2018; Akkan and Serim 2019; also Chapters 8 and 10).

Finally, national citizenship presupposes national or ethnic belonging to the imagined community as the pre-condition for granting citizenship, which is in tension with several ongoing trends. The first tension arises between an inherently particularistic national identity as the basis of rights and an increasing 'internationalization' of citizenship via international human rights law norms, which assumes universal personhood (Soysal 1994). The two pull in different directions - while the former implies limitations of rights to those sharing national identity, the latter is 'indefinitely extensible' (Leydet 2017). The second tension is between national identity and increasingly internally diverse nation states. Namely, the prioritization of national belonging amounts to the imposition of the majority culture to minorities that share a different ethnic or religious identity (Leydet 2017; Buğra 2018). An additional tension is between national (as cultural) identification and different types of identities that persons self-identify with. Members of national minorities as well as those members of national majorities who do not identify on national grounds are ascribed an identity that they do not necessarily share. Lastly, taking national identity as the basis of citizenship assumes belonging to one community, which is challenged by transnational migrations since they create overlapping memberships between territorially separated and independent polities. Persons can simultaneously belong to and have overlapping affiliations with two or more polities, which are often recognized as dual or multiple citizenships (Bauböck 2003).

As we can see, three fundamental presuppositions of national citizenship including territoriality, sedentariness and national/subnational belonging reveal boundary drawing based on power inequalities between those who meet these criteria, and thus get recognized as citizens, and those who do not meet them and, hence, have no claim to the legal status, no matter how affected they are by decisions of a particular political community (beyond or within its borders).

\subsection{BOUNDARY DRAWING AMONG CITIZENS}

Limiting the scope of justice to a territorially bounded political community is also problematic since it ignores various fault lines of justice that occur 
within the nation states, thus making the ideal of equal (national) citizenship unrealized.

Social citizenship rights were a 'pinnacle' of a modern social democratic state that according to Marshall (1950), have weakened class differentiation and secured social cohesion and integration. This view was challenged on the grounds that the extension of citizenship rights to the previously excluded groups had not translated into equality and full integration (Young 1989). Fraser argues that socio-economic and cultural injustices are both rooted in processes and practices that systematically disadvantage some groups of people vis-à-vis others, thus creating 'a vicious circle of cultural and economic subordination' (1995, p. 72). For instance, gender cultural norms are not only dominant at the domestic sphere (where women are still responsible for the care that is central to productivity), but are institutionalized in the state and the economy leading to women's economic disadvantage, which in turn makes it more difficult for them to participate in decision-making and change these norms. This shows how economic disadvantage and cultural disrespect are intertwined and justice requires tackling both through redistribution, recognition and representation (Meneses et al. 2018; see Chapter 11).

While the differential challenge was motivated by the 'struggle for recognition' taking place at the end of the 20th century, our empirical chapters unravel another paradigm shift with the emergence of 'austerity society' ${ }^{3}$ both at the level of the EU as well as its Member States. The EU response to the 2008 financial crisis was the introduction of various austerity measures which fundamentally redefined the European Social Model to make it more compatible with the neo-liberal economic model, thus giving new impetus to the struggles for redistribution. Importantly, the austerity measures are not limited to decreasing public spending, but amount to a complete institutional transformation including the politics of privatization of public services, labour market deregulation, fragmentation of labour relations and erosion of the welfare state. This has devastating effects on employment and economic security such as the loss of jobs, increased precariousness and in-work poverty (Araújo and Meneses 2018). The core feature of 'austerity society' is the increasing insistence on the 'responsibilization' of individuals for their own fate in face of technocratic solutions presented as the only possible path. The shift from collective responsibility for personal well-being of vulnerable members of a political community (which informed the European Social $\mathrm{Model}^{4}$ ) to individual responsibility for one's living conditions has thickened boundary lines. Austerity policies set back redistributive justice by introducing much stricter criteria of inclusion and reducing universal access to public goods. This has resulted in fear and insecurity among workers as well as among professionals and people depending on care and welfare benefits (Meneses et al. 2018; Anderson and Dupont 2019; Granger 2019). 
According to Fraser, injustice is ultimately about being excluded from participating as a peer in social life. Such exclusion is not accidental but results from institutionalized patterns which she defines as 'the workings of social institutions that regulate interaction according to parity-impeding cultural norms' (Fraser 2000, pp. 113-14). It may be helpful to think of these norms in terms of ethos that permeates both institutions and society. These institutionalized patterns constitute some categories of social actors as less than full members of society by them deviating from what is constituted as a dominant norm of 'normalcy'. Thus, the patterns place persons into a vulnerable position based on their personal features and traits. Even though a marginalized position is not restricted to people of a certain age, gender, ethnicity, race, able-bodiedness or religion, the risk of marginalization is higher for ascribed categories deviating from the 'normalcy' - that is, the able-bodied male of a specific age, religion and ethnicity. The parity-impeding values are institutionalized at various institutional sites which range from formal ones, including laws, public policies, administrative codes and professional practices, to more informal sites such as customs and social practices. Social subordination is 'an institutionalized relation' and as such, a serious violation of justice (Fraser 2000, p. 113). This mirrors Tilly's (2005) idea of 'durable inequality' as 'modes of social organization whereby bounded social groups are subject to systematic disadvantages in relation to dominant groups'. In their most stable form, these modes of social organization are tied to all kinds of group identities, including race, gender, ethnicity, religion, family line and national citizenship. Tilly explains that the reason why inequalities track group boundaries is 'social closure' - once members of a certain group attain control over an important good, they want to secure such advantage by closing its ranks for members of other groups. We will come back to this shortly.

Social closure is instantiated by two important features of the emerging 'austerity society' in Europe - the imperatives of 'deservingness' and 'reciprocity'. The 'deservingness' principle concerns a growing insistence on individuals being personally responsible for their circumstances and actions, and therefore deserving of consequences of their actions. The insistence on 'reciprocity' requires individuals who receive public goods to do something in return (for example, economically and/or socially contribute to society). In combination, these imperatives narrow down the spectrum of needs and consequently create rather strict boundary lines between deserving and undeserving citizens. The right to social housing, for instance, is limited to narrowly defined vulnerable groups (Granger 2019). To deserve social assistance, one has to prove that one is fully (not only partly) unable to work, or is ready to participate in public works, and is also expected to display a certain virtuous behaviour (Anderson and Dupont 2019). While access to public goods and services has always been conditional upon specific requirements, what an 'austerity society' changes 
is that these requirements are becoming stricter and more complex. The rationale of such further restrictions is that the public goods are decreasing, which in turn necessitates decreasing the number of those who can get access to it. 'Deservingness' and 'reciprocity' move an 'austerity society' away from social citizenship and a moral imperative of collective responsibility for social cohesion, towards individual responsibility for one's own well-being (Young 2011; see also Fraser and Gordon 1995). The institutionalized patterns of subordination, however, challenge the imperative of personal responsibility at a fundamental level by showing how actions of others 'block' possibilities of our actions (Young 2011), thus preventing persons from fully developing their functionings and living lives they have reason to value (Sen 1999). In other words, under conditions of institutionalized subordination and exclusion, persons are still able to make choices, but the consequences of such choices are to an important extent attributable to persons' social and economic positions rather than to their personal actions only.

\subsection{CATEGORIZATION AND DIFFERENTIATION}

The previous chapters show that differentiation is operating in every aspect of social reality; it is evidential, ubiquitous, and seemingly unavoidable. If performed carefully, without prejudice and with the purpose of enhancing people's capabilities and functions, differentiation can be a valuable instrument in reaching justice in a world characterized by human diversity. For instance, in assigning home care to elderly and disabled persons, insurance companies, governments and care providers cannot avoid differentiating between the able-bodied and the less able-bodied to determine who needs what kind of support, and given the scarce resources, who will receive how much financial compensation (Anderson and Dupont 2019; Knijn 2019; see also Chapter 10). By understanding and recognizing individual capacities and meeting them, differentiation might assure that the proper means reach the people in need of them, while avoiding fraud and abuse.

The chapters show that in practice differentiation is too often based on categorization of assumed and ascribed group characteristics of persons who deviate from 'normalcy', and as such get excluded from participatory parity. The case of care exemplifies the inherently complicated relationship between redistributive, recognitive and representative justice in which two major paradigms are conflicting. The paradigm of 'independent living' is embraced and prioritized by the EU and most of the Member States as a principle of recognitive justice which meets the claims of social movements such as the Independent Living Movement, which mainly represents disabled populations. The same paradigm influenced social policies concerning elderly populations as outlined in the Active Ageing agenda of the EU. What is overlooked in this 
agenda is that neither elderly people nor disabled persons can be categorized according to one single norm. In this case, the dominant categorization (disabled, aged) fails to differentiate among persons that legitimately have different claims, which in turn makes the provision of public goods insufficient to secure participatory parity (Knijn 2019). Moreover, independent living necessitates proper facilities and conditions in support of it, which shows that it also has an important redistributive justice dimension with regard to both those in need of care and those providing it. When it comes to the status of care providers, the European Commission (2013) inspired by the social investment paradigm (the idea that the investment in human capital should foster individual and social prosperity) addressed that issue by pleading for compensation for the working time of carers because of foregone alternative employment and reduced accrual of social protection (Knijn 2019; see also Chapter 9). Such measures can improve gender equality in care work as well as appropriate long-term care. This shows that in principle, recognitive and redistributive justice could be combined when an adequate differentiation takes place. Though in times of scarce resources, austerity measures and the lack of acknowledgement of the implications for care giving by female family members a trade-off is most likely (Knijn 2019). As to children with disabilities, Salát (2019) signals the same kind of problems. She concludes that no educational system in the countries under study fully realizes inclusive education or even sees it is possible for everyone. While all countries except Hungary maintain the possibility of sending pupils with a disability into special education, the lack of finances, resources and staff, or negative effects of outsourcing special education to the market, hamper its realization.

Hence, while differentiation might be unavoidable to do redistributive justice in heterogeneous societies, the cases of redistributing public goods to care for elderly and disabled persons, and to educate disabled children show that drawing category-based boundary lines is a complex matter due to the non-homogeneity of the categories (Buğra 2018; see also Chapter 9). Following Sen (1992) one could say that in the process of defining and providing the necessary means and conversion factors to enhance capabilities and functionings, boundary drawing appears as a complex normative mixture of expected identities and 'deservingness', getting shape in more concrete criteria with regard to various social domains. In constructing deservingness criteria of equity, needs, conditionality, sameness, attitude and/or merit/reciprocity (Miller 1999; Oorschot van 2000) are applied that define whether people will receive public support that adequately meets their needs. These criteria reshape the identities of mainly vulnerable populations by (re-)identifying older and disabled people as autonomous, and self-relying, or as family members instead of individual citizens, and when efforts to contribute to society become conditional for receiving benefits, social housing and care. Therefore, 
categorizing vulnerable people and minorities goes beyond pure categorical thinking in terms of existing categories such as age, gender, race, ethnicity or able-bodiedness. Rather, it works via redefining these identities of vulnerable populations in categories of recognized deservingness by policing their needs in the context of redistributing scarce resources. Such (re)categorization of persons then makes it more difficult for the provision of public goods to secure participatory parity. In sum, misrecognition of individual differences due to inadequate categorization often results in maldistribution of resources.

\subsection{CATEGORIZING FAULT LINES OF (IN)JUSTICE}

According to Fraser, boundary drawing amounts to institutionalized patterns of exclusion that can be present in different social domains including institutions, public policies and social practices. The normative significance of these patterns is that they amount to the exclusion from participatory parity and as such constitute injustice. When it comes to the EU, identity-based boundary drawing at a formal, institutional level is legally allowed only to prevent discrimination. Minorities are typically legally recognized in order to compensate for misrecognition and maldistribution. According to Article 3(3) Treaty on the European Union (TEU), the Union 'shall combat social exclusion and discrimination, and shall promote social justice and protection' (TEU 2008). Given the complex legal structure of the EU, lots of legal incentives to protect minorities and vulnerable groups get lost in the process of translating the European legal standards to concrete legal entitlements of those residing in the EU, resulting in a wide gap between the original idea of justice as an equal entitlement to various rights and the daily experiences of members of these groups. In this section, we will capture this gap by categorizing the most salient fault lines of injustice, while acknowledging that these necessarily interact since humans have multiple identities manifested in different contexts and social spheres. For instance, it may appear confusing and against social expectations if the hard-working entrepreneur goes bankrupt and suddenly becomes a welfare recipient with debts, or if the construction worker becomes disabled and must ask for healthcare and income support. We will set these complications aside in order to illuminate the general boundary drawing that characterizes the European ethos.

Age-related categorization at the labour market typically exemplifies a default line of justice. Younger generations are not excluded from the labour market because of their age, they are excluded because the neo-liberal labour market offers mainly precarious jobs to newcomers, the reduction of social protection and the prioritization of economic above social rights. By consequence, younger generations are excluded from participation in permanent jobs during and after the economic crisis (Meneses et al. 2018; also Chapter 
11), thus facing the 'social closure'. Tilly (1999) distinguishes two aspects of social closure: 'opportunity hoarding' which refers to denying access to the goods in question to outsiders, and 'exploitation', which means allowing access but 'only in ways that exclude out-groups from the full value added of their efforts' (Tilly, as discussed in Anderson 2010, p. 8). Tilly considers 'opportunity hoarding' not so much to be motivated by out-group antipathy to young ones, women, disabled people and migrant care workers but by in-group favouritism expressed in protecting vested interests of those already 'in'. 'Opportunity hoarding' exists not only regarding being employed, but also what kind of employment one can get. In this respect, the fundamental change taking place in the European labour market is through the introduction of 'flexicurity'. Initially, the concept combined the flexibility in the labour market with social security, but in the light of the 2008 crisis, it often omits the latter - many young people find themselves working in insecure, part-time jobs, while having very limited access, or no access at all, to income compensation (Araújo and Meneses 2018; see also Chapter 11).

Second, ethnicity-based categorization takes multiple forms due to national, cultural and institutionalized path dependency. This takes place despite European Conventions and Treaties as well as the case law of the European Court of Justice legally prohibiting discrimination. For instance, the concept of national minorities still defines groups of people once belonging to and still present in the previous continental empires of Austria and Turkey. In both countries the rights of recognized ethnic or religious minorities to preserve and foster their ethnicity and language is guaranteed, protected and provided for (Meier and Vivona 2018; Buğra and Akkan 2019; see also Chapter 9). Interestingly, in these countries migrants who arrive from territories beyond the borders of the former empire are not included in the concept of 'minorities'; instead, they are migrants with a much weaker citizenship status than members of the recognized national minorities. The former oversees empires such as the Netherlands, Portugal and the UK have more complicated categorizations of minorities. In addition to religious and subnational minorities, these countries harbour previously colonized oversees racial and ethnic minorities that are defined as different from natives, as in the UK and the Netherlands, or whose difference is denied, as in Portugal, despite obvious reasons for recognizing it (Anderson et al. 2018; Araújo and Brito 2018; Hiah and Knijn 2018; see also Chapter 8). Categorization of minorities by the recognition of their ethnic, religious or racial difference from the majority population pressures members of minorities to constantly prove that they deserve membership in the political community (Lepianka 2018). This raises substantive justice dilemmas about historical memorization (Akkan and Hiah 2019), educational discourses, law and practices (Lepianka 2019; Salát 2019), welfare regimes (Anderson and Dupont 2019) and voting rights (Theuns 2019). Anderson addresses this in 
Chapter 8 by analysing the minority group par excellence-Roma. None of the studied Member States has been able to adequately include Roma as national citizens with minority rights that fit in with cultural and institutional regimes; instead they all struggle with the conflictual relationship between recognitive, redistributive and representative justice at all governmental levels, institutionalized and social practices. These are reflected in individual dilemmas of categorized versus preferred identities: educational systems systematically undervalue the capacities and cultural heritage of minority group children; welfare professionals express distrust in Roma applicants for benefits; migrant care workers are exploited; and the denial of the colonial past and suppression of oversees populations by European nation states offends fellow citizens descending from slavery and modern colonialism. All three justice principles are at stake here: redistributive justice because of the reciprocity principle that demands that contributing and receiving should go together while in practice individuals are judged according to the social perception of group behaviour, which goes hand in hand with scarce resources for maintaining minority cultural practice; recognitive justice because majority as well as minority cultures have problems with meeting universal human rights by denying diversity and pluralism or claiming exception from human rights; and representative justice because potential spokespersons fear to identify with their minority group because it might result in ostracism (Anderson and Dupont 2018; Chapter 8).

Avoiding gender-based categorizations has been and still is one of the more successful aims of the EU in overcoming gender inequality. For instance, equal pay for equal work, equal pensions and equal contracts were all initiated by the EU and accepted by Member States to various degrees. Nonetheless, gendered injustice still prevails. We identified five obstacles to gender justice: (1) the EU paradigm of autonomous individuals who move for employment without the burden of family life, and buy what they need on the free market; (2) the mainly soft law guaranteeing social rights fails to protect equal payment and care facilities for family members (children, frail elderly and disabled kin); (3) the undervaluation of formal regulated care work as part of service work; (4) the distinction between legally regulated public sector employment and mainly unregulated family care work; and (5) the dependency paradigm stating that autonomy implies independency from the state which goes at the cost of family independency. Hence, enduring gender justice cannot be secured by the institutionalized EU gender-equality regulations only. Just like in the case of age and disability-related injustice, it is the concept of 'dependency' as elaborated by Anderson et al. (2017; see also Chapter 10) that redefines women's identity as the criterion for social closure. The EU's gender-equality principle recognizes women as active and autonomous agents being capable of running their own life. This contributes to human dignity and women's capability to live the life they value. The effect of austerity policies, however, is the reduction of 
public support and structural conditions for participatory parity. By ignoring interdependency as a cornerstone of human relations and in times of austerity, re-familialization of care dependency and flexibilization of the labour market undermines gendered justice (Meneses et al. 2018; Knijn 2019).

All these categorizations show that the European ethos is still characterized by the imperative of exclusion reinforced by the emergence of 'austerity society' and permeating both formal and informal institutions in the EU and the Member States. In reaction, positive initiatives of civil society actors take place across the EU with regard to all three dimensions of justice. Recognitive justice, for instance, has gained a lot due to the 'independent living' movement having secured the conditions for life a disabled person has a reason to value in the EU (Knijn 2019; Chapter 9). Regarding representative justice, civil society organizations (CSOs) play an important role in political representation of Roma. Anderson and Dupont point out that stigmatized identities can hamper institutionalized forms of political participation but also stimulate CSOs as non-electoral forms of representation (Anderson and Dupont 2018). While such representation cannot fully replace the electoral one, and many Roma still do not feel represented, it is one positive step towards the recognition and representation of Roma in at least some EU Member States. The situation is most grave regarding redistributive (in)justice. Despite growing awareness about injustice, it is very difficult to mobilize people to fight against it. For instance, young people became 'a very vulnerable working mass' (Meneses et al. 2018, p. 64), while the third country nationals are afraid to openly oppose the working conditions since the loss of employment would lead to losing their residency too. Mobilization against socio-economic injustice is also difficult because of the ongoing trend of 'individualizing' relations between employees and employers by limiting unionizing and decentralizing collective bargaining mechanisms. Attempts to antagonize deprived individuals one against another with regard to getting social benefits (for example, needy versus working poor) do not help either. Nonetheless, a significant mobilization against austerity measures takes place across Europe. Protestors demand a new model of democracy including the restoration of the European Social Model based on equality and solidarity. While these are justifiable demands, it seems inadequate to fight for them at national levels since their cause is global - the subordination of individual and collective rights to decent life to the imperative of economic growth that benefits a very tiny minority of the world's population (Meneses et al. 2018). 


\subsection{CONCLUDING REMARKS: REFINING THE THEORETICAL FRAMEWORK}

We have defined the ETHOS's theoretical framework as based on the Fraserian framework as recognitive, representative and redistributive justice. All three dimensions of justice are necessary to secure 'participatory parity' - participating as a full member in the social and political life of one's society (Fraser and Honneth 2003). These ideal types represent the theoretical foundation of a non-ideal European theory of justice. The other foundation are empirical studies on the institutional regulations and practices, social relations and lived experiences of members of vulnerable groups captured by the categories of boundary drawing within the EU. These categories take place along the lines of citizenship, age, ethnicity, gender and able-ness, some of which are taken to constitute a dominant 'normalcy' in the studied societies, whereas all those that depart from such a norm along any of these lines are taken to be deviant in some sense, and as such, justifiably excluded from a particular 'inner' scope of justice. These categories interact with what we take to be the core norms of the emerging 'austerity society' in the EU - the norm of 'deservingness' and 'reciprocity'. Persons are defined as 'deserving' or 'undeserving' by virtue of sharing an identity or having particular personal traits, and by whether and what they contribute to society. This shows the fundamental contradiction in the emerging 'austerity' society - a growing insistence on personal responsibility for one's life circumstances while at the same time there are many fault lines of justice that block persons' opportunities and actions. To wit, there is an imperative that people are personally responsible for the way they live and what kind of opportunities they have at the time when so little actually depends on their actions and beliefs. This fundamental contradiction then serves as the basis for refining our preliminary ideal types of justice.

Within the Fraserian framework, the ideal types draw attention to the existence of boundary drawing as institutionalized patterns of subordination. Based on our analysis, we add that these patterns, which are especially salient in the 'austerity society', come as a result of institutionalized and social practices in the name of those embodying the 'normalcy' and deciding what recognitive, redistributive and representative justice for everyone else is. This is further complicated by the fact of the multi-layered structure of justice in the EU. While the Fraserian framework of justice does not clearly distinguish between different sites of institutionalized exclusion, our findings show that it is the EU with other supranational levels that are the most important site for recognitive justice by strongly promoting minority rights and anti-discrimination policies. At the lower level governments, however, we see processes of boundary drawing either by fault or default in which recognitive justice principles 
fragment or even fade away. As to redistributive justice, there is no such clear trickling down of principles. The EU as supranational entity has competences in economic and monetary policies, while redistributive policies are reserved for the national level. Such division of competences is determined by the national governments of the Member States. Both the EU and the national governments of the Member States created a perfect vacuum of irresponsibility, in which they can blame each other for most of the perils those residing in the EU face. This suggests that Europe is characterized by justice in default. Justice values and norms are present in the official rhetoric, less so in practice. Given that the EU is a dynamic sui generis organization that constantly keeps changing, there is room for optimism that principles of justice may be actualized in practice too. ${ }^{5}$

\section{NOTES}

1. There is a distinction between abstractions and idealizations in the sense that the former brackets some known truths, whereas the latter makes some false assumptions about the real world. While idealizations necessarily imply abstractions, it does not hold the other way around (see O'Neill 1989, pp. 207-9).

2. To establish a connection between affectedness and recognition of the legal status of citizens further arguments are needed. First, as Fraser points out, we need the normative criterion to decide which kind of affectedness is normatively relevant. In her view, such a criterion is the 'all-subjected principle' - all those who are subjected to a given governance structure have a moral standing as subjects of justice in relation to it (2009, pp. 65-6). Second, we also need a substantive argument for why even a normatively relevant affectedness entails the entitlement to inclusion and rights of participation (see Miklosi 2012). Since this is not the place to engage with these substantive issues, we will set them aside.

3. Ferreira (2016) defines 'austerity society' as characterized by the fear as a source of legitimacy (prompted by predictions of catastrophic scenarios); the emergence of a new constellation of power that combines elected and unelected power; and the destabilization of the normative structure with the use of a right of exception.

4. The European Social Model rests on six pillars: increasing minimum working rights; universal and sustainable social protection; inclusive labour markets; strong and well-functioning social dialogue; public services; and social inclusion and social cohesion (Araújo and Meneses 2018, p. 9).

5. It is noteworthy that recently there have been some positive steps with regard to reviving the European Social Model at the EU level, such as the new Social Pillars, but it remains to be seen whether they will have any actual effect.

\section{REFERENCES}

Akkan, Başak and Jing Hiah (2019), 'Historical memory and the practice of commemoration in public space - mapping moral sentiments of opinion leaders', ETHOS report D4.5, accessed 11 November 2019 at https://ethos-europe.eu/. 
Akkan, Başak and Simla Serim (2019), 'Commodified care relations: Elderly people with disabilities and migrant care workers in Turkey', country report for ETHOS report D5.3, accessed 10 November 2019 at https://ethos-europe.eu/.

Anderson, Benedict (1983), Imagined Communities: Reflections on the Origin and Spread of Nationalism, London: Verso.

Anderson, Bridget (2018), 'Justice, care and personal assistance', ETHOS report D5.3, accessed 22 February 2020 at https://ethos-europe.eu/.

Anderson, Bridget and Pier-Luc Dupont (2018), "'How does it feel to be a problem?" What we can learn about justice as political representation from empirical case studies', ETHOS report D5.2, accessed 9 November 2019 at https://ethos-europe .eu/.

Anderson, Bridget and Pier-Luc Dupont (2019), 'Just deserts? Justice, deservingness \& social assistance', ETHOS report D5.5, accessed 6 November 2019 at https://ethos -europe.eu/.

Anderson, Bridget, Claudia Hartman and Trudie Knijn (2017), 'Report on the conceptualisation and articulation of justice: Justice in social theory', ETHOS report D5.1, accessed 7 November 2019 at https://ethos-europe.eu/.

Anderson, Bridget, Dora-Olivia Vicol, Pier-Luc Dupont and Julia Morris (2018), 'Political representation and experienced recognition among Roma in the UK', country report for ETHOS report D5.2, accessed 4 November 2019 at https://ethos -europe.eu/.

Anderson, Elizabeth (2010), The Imperative of Integration, Princeton, NJ: Princeton University Press.

Araújo, Sara and Laura Brito (2018), 'Tensions between institutionalised political justice and experienced (mis)recognition: Portuguese case study on the experiences of Roma communities', country report for ETHOS report D5.2, accessed 7 November 2019 at https://ethos-europe.eu/.

Araújo, Sara and Maria Paula Meneses (2018), 'The effectiveness of social dialog as an instrument to promote labour and social justice', ETHOS report D6.4, accessed 5 November 2019 at https://ethos-europe.eu/.

Bauböck, Rainer (2003), 'Towards a political theory of migrant transnationalism', International Migration Review, 37 (3), 700-23.

Buğra, Ayse (2018), 'Report on a theoretical review of the conceptualization and articulation of justice in political theory', ETHOS report D4.1, accessed 20 February 2019 at https://ethos-europe.eu/.

Buğra, Ayse and Başak Akkan (2019), 'Discourses on minorities (and vulnerable groups) access to education, inclusionary and exclusionary aspects', ETHOS report D4.3, accessed 3 November 2019 at https://ethos-europe.eu/.

European Commission (2013), 'Long-Term Care in Ageing Societies - Challenges and Policy Options. Towards Social Investment for Growth and Cohesion - Including Implementing the European Social Fund 2014-2020', Communication from the Commission to the European Parliament, The Council, The European Economic and Social Committee and the Committee of the Regions, Social Fund 2014-2020, Brussels, 20.2.2013, SWD (2013) 41 final.

Ferreira, António (2016), 'The politics of austerity as politics of law', Oñati Socio-Legal Series, 6 (3), 496-519.

Fraser, Nancy (1995), 'From redistribution to recognition', New Left Review, I (212) (July/August), 68-93.

Fraser, Nancy (2000), 'Rethinking recognition', New Left Review, 3 (May/June), 107-20. 
Fraser, Nancy (2007), 'Identity, exclusion, and critique: A response to four critics', European Journal of Political Theory, 6 (3), 305-38.

Fraser, Nancy (2009), Scales of Justice: Reimagining Political Space in a Globalizing World, New York: Columbia University Press.

Fraser, Nancy and Linda Gordon (1995), 'A genealogy of dependency: Tracing a keyword of the U.S. welfare state', Signs, 19 (2), 309-36.

Fraser, Nancy and Alex Honneth (2003), Redistribution of Recognition? A Political-Philosophical Exchange, London and New York: Verso.

Granger, Marie-Pierre (2019), 'Coming "home": The right to housing, between redistributive and recognitive justice', ETHOS report D3.5, accessed 3 November 2019 at https://ethos-europe.eu/.

Hiah, Jing and Trudie Knijn (2018), 'Country report on the current and historical minoritization of Roma minorities in the Netherlands', country report for ETHOS report 5.2, accessed 3 November 2019 at https://ethos-europe.eu/.

Knijn, Trudie (2019), 'Boundary lines between private and public care; living independently at home or in a home', ETHOS report D5.4, accessed 8 November 2019 at https://ethos-europe.eu/.

Knijn, Trudie and Dorota Lepianka (2018), 'Report containing a conceptual framework for integration of findings', ETHOS report D7.1, accessed 4 November 2019 at https://ethos-europe.eu/.

Lepianka, Dorota (2018), 'Justice in European political discourse - comparative report of six country cases', ETHOS report D4.2, accessed 8 November 2019 at https:// ethos-europe.eu/.

Lepianka, Dorota (2019), 'Mapping the construction of justice and justice related tensions in Europe - a comparative report of national media debates on (minority) education in six countries', ETHOS report D4.4, accessed 3 November 2019 at https://ethos-europe.eu/.

Leydet, Dominique (2017), 'Citizenship', in Edward N. Zalta (ed.), The Stanford Encyclopedia of Philosophy (Fall 2017 edition), accessed 5 November 2019 at https://plato.stanford.edu/archives/fall2017/entries/citizenship/.

Marshall, Thomas Humphrey (1950), Citizenship and Social Class, Cambridge: Cambridge University Press.

Meier, Irene and Maddalena Vivona (2018), 'The tension between institutionalised political justice in Austria and Roma's experienced (mis)recognition', country report for ETHOS report D5.2, accessed 3 November 2019 at https://ethos-europe.eu/.

Meneses, Marie Paula, Sara Araújo, Sílvia Ferreira and Barabara Safradin (2018), 'Comparative report on the types of distributive claims, interests and capabilities of various groups of the population evoked in the political and economic debates at the EU and at the nation state level', ETHOS report D6.2, accessed 2 November 2019 at https://ethos-europe.eu/.

Miklosi, Zoltan (2012), 'Against the principle of all-affected interests', Social Theory and Practice, 38 (3), 483-503.

Miller, David (1995), On Nationality, Oxford: Oxford University Press.

Miller, David (1999), Principles of Social Justice, Cambridge, MA: Harvard University Press.

Nagel, Thomas (2005), 'The problem of global justice', Philosophy \& Public Affairs, 33 (2), 113-47.

O'Neill, Onora (1989), Constructions of Reason: Exploration of Kant's Practical Philosophy, Cambridge: Cambridge University Press. 
Oomen, Barbara and Alexandra Timmer (2017), 'Report on four of fewer freedoms: Contested conceptions of justice in Europe between 1941 and 1957', ETHOS report D3.2, accessed 3 November 2019 at https://ethos-europe.eu/.

Oorschot, Wim van (2000), 'Who should get what, and why? On deservingness criteria and the conditionality of solidarity among the public', Policy \& Politics, 28 (1), $33-48$.

Salát, Orsolya (2019), 'A comparative report on the right to education: An assessment of the legal framework of six countries from the perspective of recognitive and redistributive justice', ETHOS report D3.6, accessed 3 November 2019 at https:// ethos-europe.eu/.

Sen, Amartya (1992), Inequality Reexamined, Cambridge, MA: Harvard University Press.

Sen, Amartya (1999), Development as Freedom, New York: Alfred E. Knopf.

Soysal, Yasemin Nuhoglu (1994), Limits of Citizenship, Chicago, IL: University of Chicago Press.

TEU (2008), Consolidated Version of the Treaty on the European Union, 2008, accessed 10 November 2019 at https://eur-lex.europa.eu/LexUriServ/LexUriServ.do ?uri=OJ:C:2008:115:0013:0045:EN:PDF.

Theuns, Tom (2019), 'A comparative report on the legal rules and practices regulating the exercise of the right to vote (eligibility and representation) in local, national and EU elections of marginalised groups', ETHOS report D3.4, accessed 8 November 2019 at https://ethos-europe.eu/.

Theuns, Tom, Sem de Maagt and Trudie Knijn (2019), 'Framework paper on the methodological tool for reflecting and reviewing empirical findings of ETHOS', ETHOS report D7.2, accessed 13 November 2019 at https://ethos-europe.eu/.

Tilly, Charles (1999), Durable Inequality, Berkeley and Los Angeles, CA: University of California Press.

Tilly, Charles (2005), Identities, Boundaries, and Social Ties, Boulder, CO: Paradigm.

Walzer, Michael (1983), Spheres of Justice: A Defense of Pluralism and Equality, New York: Basic Books.

Young, Iris M. (1989), Justice and the Politics of Difference, Oxford: Oxford University Press.

Young, Iris M. (2011), Responsibility for Justice, Oxford: Oxford University Press. 